\title{
THE IMPACT OF EDUCATION ON ECONOMIC GROWTH: THE CASE OF INDIA
}

\author{
Sylvie Kobzev Kotáskovál, Petr Procházka², Luboš Smutka², Mansoor Maitah², \\ Elena Kuzmenko², Markéta Kopecká², Vladimír Hönig³
}

\begin{abstract}
${ }^{1}$ Department of Humanities, Faculty of Economics and Management, Czech University of Life Sciences in Prague, Kamýcká 129, 16500 Praha 6-Suchdol, Czech Republic

${ }^{2}$ Department of Economics, Faculty of Economics and Management, Czech University of Life Sciences in Prague, Kamýcká 129, 16500 Praha 6-Suchdol, Czech Republic

${ }^{3}$ Department of Strategy, Faculty of Business Administration, University of Economics, Prague , W. Churchill Sq. 1938/4, Prague 3, 130 67, Czech Republic
\end{abstract}

\begin{abstract}
KOBZEV KOTÁSKOVÁ SYLVIE, PROCHÁZKA PETR, SMUTKA LUBOŠ, MAITAH MANSOOR, KUZMENKO ELENA, KOPECKÁ MARKÉTA, HÖNIG VLADIMÍR. 2018. The Impact of Education on Economic Growth: The Case of India. Acta Universitatis Agriculturae et Silviculturae Mendelianae Brunensis, 66(1): 0253-0262.

There exists an enormous interest in clarification of the relationship between education and economic growth. Over the past 30 years, there have been conducted studies by economists about the connection between education and economic growth. There are actually many publications which provide strong evidence that suggests a correlation between the two. This paper attempts to build upon previous publications and to introduce a unique insight along with contemporary evidence about the relationship between education and economic growth in India from 1975 to 2016 by foc using on primary, secondary and tertiary levels of education. The relationships are examined by utilization of econometric estimations with the Granger Causality Method and the Cointegration Method. These methods are used to create models that could shed light on the claim that education plays a central and significant role in economic growth of India which could consequently be used as an example for similar countries in Asia or around the world. The findings of this work show that there is compelling evidence proving a positive connection between education levels and economic growth in India which might influence governmental actions and shape the future of India.
\end{abstract}

Keywords: education, gross enrolment rate, economic growth, impact, India, Asia

\section{INTRODUCTION}

Economic growth of a country may get hampered due to a number of different factors. Example of such a factor is natural resources - land, crude oil, water resources and agro-based industry (for example sugar industry). In many countries, natural resources play very important role regarding economic growth (Maitah and Smutka, 2016; Maitah et al., 2016; Smutka et al., 2015; Řezbová et al., 2015; Kharcheva et al., 2016). Another example is government policies which has always had a significant influence on economic growth. Specifically, fiscal policy, monetary policy and policies related to foreign exchange rates play significant role regarding economic growth of a country. Avoiding significant overvaluation of the currency is one of the most robust imperatives that can be gleaned from the diverse experience with economic growth around the world (Maitah, M., et al., 2016; Clark et al., 2015; Maitah et al., 2017; Maitah et al., 2014). There is also a significant influence of FDI on education system and economic growth. Singh Kalpan (2016) focuses in his work on impact of FDI on tertiary level of education where the impact should be positive and improve the quality of education and consequently contribute to the national growth of the economy since human capital is one of the key determinants of economic growth for both developing and advanced economies. From many publications can be deduced that FDI has an impact on enhancement of human capital, especially in 
developing countries. The economic growth of India averaged 1.67 percent from 1996 to 2016. The economic growth has been based primarily on tertiary sector (services). Trade, communication, financing, insurance, business services and social and personal services account for approximately 60 percent of GDP. Primary sector of India generates around 12 percent of the output. On the other hand, it employs more than 50 percent of the labor force. This might be due to illiteracy of inhabitants. In 2011, only 66 percent of females in India were literate (males - 82 percent). Total gross enrollment in primary education was 108 percent (some students were repeating), 74 percent in secondary education and only 25.5 percent in tertiary education (mainly due to high poverty level). India, as a developing country, typically lacks the skill sets and knowledge required to adopt new technology and to implement it to the local environment. Thus, implementing a learning process becomes a necessity. More than $50 \%$ of Indian children drop out of school at primary level. This is caused by a lack of literacy and a failure of governmental education programs within the country (National Portal of India, 2015). According to the official government programme, the level of expenditure for education in India should be $6 \%$ of its GDP. However, the reality is that only $3 \%$ of the GDP is spent on education (Aggarwal, 2008). Therefore, it is very important to clarify the relationship between education and economic growth and how they influence each other.

Objective of this paper is to assess the economic growth of India in relation to education levels in India during 1975 to 2016. In the first part of this work there is a literature review and the issue of the topic is discussed. The next part focuses on analysis of the data collected and the last part of the work is conclusion of the research. Focus will be on three different level of education which is quite unique approach. The information resulting from this innovative research is crucial as it might provide valuable information for the government in India, as there is an overhaul of education system taking place, to take actions in the direction that would lead country to more prosperous future as the education systems, and education in general, of the country influence economic growth of a country which also impacts foreign countries related to India. Relationship of education and economic growth will be examined on the basis of econometric models, specifically the Granger causality method and the cointegration method. There are numerous reasons why scholastic quality is deficient in India. That is the reason behind education system overhaul and various debates. Researchers debate whether changes in educational attainment levels affect the long-term growth rate of the economy. According to Wamboye (et al., 2015) education provides essential knowledge, techniques, skills and information for each individual to define their role toward family and society. In addition, education also provides the ability to combat such social evils as ignorance, injustice, corruption, violence, disparity and communalism, which many times serve as obstacles to the progress of a nation and economic growth (Glewwe, P. and M., Kremer, 2006; Stevens, P. and M., Weale, 2003).

Increase of employment and focus on structuralizing of the economy are key tools how to increase the level and quality of education. Encouraging and expanding opportunity for career training are crucial too. Another issue is that education is not free for all Indians, for instance, education in the technical area is one of the most important and also one of the most expensive branches in India. Tools mentioned above need a government support in order to be successful for the economic growth. Without significant education reform India cannot expect positive changes to take place as significant social and economy structuralisation is needed (D'Aleo et al., 2017).

\section{Literature Review}

According to Kingdon (2007) the level of education in India is better than the education level in countries such as Pakistan or Bangladesh. Although, it is still low in comparison to other Asian countries such as Korea, Japan or Taiwan. As some of the countries with a high level of education (e. g. Taiwan) have a strong economy it brings a question whether these two factors are connected. Many researchers have noticed this fact and conducted a research on this topic.

Example is Self and Grabowski (2004) as they focused in their research on the impact of different education levels on India's economic growth. Their study is built on the premise that changes in education are responsible for changes in the economic growth. They tested whether the relationship between education level and economic growth is different when population is divided into groups by gender. To measure education level, they used data over 30 years (1966-1996) with enrolment ratios as a proxy for the flow of human capital. Another measurement was the change of the mean in the years of education at each level of education. This measurement basically represents the growth rate of human capital stock. As a result, Self and Grabowski (2004) proved that primary and secondary education is not just strongly correlated with the economic growth of the country but it also has a strong casual impact on the economic growth in India. Their analysis also proved that all education levels are related to each other. Nevertheless, the result also showed differences between the primary, secondary and tertiary level of education in terms of their impact on economic growth as tertiary education does not seem to have causal impact on the economic growth.

Their research had some shortcomings. Example could be that the data were collected for the time span in which reliable data were not recorded precisely or at all. Also, the data might be considered obsolete as in 20 years there might 
be changes in the country, environment and economy. Therefore, their study most likely does not represent contemporary situation. In contrast, according to Easterlin (1981), Behrman (1987), Azariadis \& Drazen (1990) the lack of any impact from human capital stock at the secondary level reduces the reliability of the estimate of the impact of the enrolment rate as a variable.

In another study from Tilak (2007), the author is attempting to prove that secondary and tertiary education levels are not necessary for the economic growth of the country, while post elementary education is more important, especially for the reduction of poverty, a decrease of infant mortality, an increase in life expectancy and particularly for the economic growth within the country. The results proved that there is a relationship between post elementary education and development. Also, the results show that gender inequality in education is one of the biggest problems in Indian society. This is especially valid fact for females from rural areas and lower socioeconomic backgrounds (Ruther, White, Kanh, 2016). The gender gap unveiled the elements which affect the relationship between the level of education and economic growth. The higher levels of education the higher salary of an individual which is also a common sense but in the case of India it only amplifies the inequality in Indian society.

Many other publications focused on researching the relationship of the level of education and economic growth of the country. Example of such publication can be Lin (2003) where is studied relationship of economic growth, education and also the technical progress. As he has proven that all the variables are connected and positively correlated. In his other work, Lin (2003) researched relationship of economic development and higher education which he has found to be also positively correlated. Some publications also focused on the similar topic in broader region such as East Asia. In his work, McMahon (1998) also identified positive relationship between education level and economic growth.

Even though every researcher had different approach to their work the results seem to be similar or the same. The question is whether the relationship of education level and economic growth has changed in India and whether there are other causes related to these two variables. Clarification and specification of the impact of education on economic growth might be consequently considered as a valuable information. This brings us to two hypotheses that are worth analyzing. Increased graduation rates in secondary education have a positive impact on economic growth in India, especially for the female population. Another hypothesis is that the level of education has an indirect impact on economic growth through fertility rate in India.

\section{MATERIALS AND METHODS}

This paper examines the impact of education levels on economic growth in India between 1975 to 2016. It also analyzes the gender issue in regards to education and economic growth within the country. The evaluation of the impact of the primary, secondary and tertiary education on economic growth is conducted. Enrolment rates and average years of schooling at every level will be used to measure as a proxy for human capital stock. Growth rate and gender are measured as the change in the mean years of schooling.

Data used in the empirical part were collected from the World Development Indicators database which is provided by the World Bank. It contains the enrolment variables and GDP product value at market prices (2005 constant USD). The time period for which the data are analyzed is from 1975 to 2016. The data for GDP per capital are annual values. However, data on average years of schooling are available only at five-year intervals. The exponential growth rate is calculated between the first and fifth year and the interim years are interpolated. Primary, secondary and tertiary enrolment rates are based on UNESCO's (2002, 2006, 2010) classification. The analysis of the growth rate of human capital stock is conducted separately for the male and female population.

\section{Granger Causality}

Granger (1969) defined causality as testing whether there is an influence of lagged information on a variable $\mathrm{X}$ which provides statistically significant information about a variable $Y$ in the presence of lagged Y. In order to determine the causal relationship between education and economic growth, the following hypothesis is tested:

$$
\begin{aligned}
& H_{0}: E\left(\Delta y_{t} / \sum_{i=1}^{n} \Delta y_{t-i}, \sum_{j=1}^{m} \Delta y_{t-j}, \sum_{i=1}^{m} \Delta z_{t-j}\right)= \\
& =E\left(\Delta y_{t} / \sum_{j=1}^{m} \Delta y_{t-i}, \sum_{j=1}^{m} \Delta z_{t-j}\right)
\end{aligned}
$$

For all $\mathrm{m}>0$-No Granger causality. Against the alternative of:

$$
\begin{aligned}
& H_{1}: E\left(\Delta y_{t} / \sum_{i=1}^{n} \Delta y_{t-i}, \sum_{j=1}^{m} \Delta y_{t-j}, \sum_{i=1}^{m} \Delta z_{t-j}\right) \neq \\
& \neq E\left(\Delta y_{t} / \sum_{j=1}^{m} \Delta y_{t-i}, \sum_{j=1}^{m} \Delta z_{t-j}\right)
\end{aligned}
$$

$\Delta y$ represents the first difference of the log of per capita GDP, $\Delta z$ represents the first difference of the log of the capital labour ratio, and $\Delta x$ represents the first difference of the log of the education variables for each education level, $m$ and $n$ are orders of lag for appropriate variables.

\section{Stationarity Test}

Before conducting any of the tests above, all of the relevant series are tested for stationarity, since standard inference procedures do not apply to 
regressions which contain an integrated dependent variable or integrated repressors. A formal method to test for stationarity of a series is the Unit root test. To this effect, the standard Augmented Dickey Fuller (ADF) test and the Phillips-Peron (PP) tests must be utilized and all variables should be found stationary. Next, the following model is formulated to test the causal relation:

$\Delta y_{t}=\delta_{0}+\sum_{j=1}^{m 1} \delta_{1 j} \Delta y_{t-j}+\sum_{j=1}^{m 2} \delta_{2 j} \Delta z_{t-j}+\sum_{j=1}^{m 3} \delta_{3 j} \Delta x_{t-j}+e_{1 t}$

For the lagged variables appearing on the right hand side, the number of lags is determined using the Akaike Information Criterion (AIC) and Schwartz Criterion (SC). Adding lagged values of the dependent variable on the right-hand side, other than fulfilling the Granger causality requirement, also reduces or eliminates the problem of spurious results due to serial correlation. (Self and Grabowski, 2004).

A major part of the analysis depends on the choice of lag length since the results of the causality tests rely heavily on the time lags being imposed. If $\delta_{2 j}$ and/or $\delta_{3 j}$ are found to be statistically significant and different from zero, we reject $H_{0}$ and accept $H_{1}$. (Self and Grabowski, 2004) In testing for the causal impact of gender based education on growth, the above equation is modified as:

$$
\begin{aligned}
& \Delta y_{t}=\delta_{0}+\sum_{j=1}^{m 1} \delta_{1 j} \Delta y_{t-j}+\sum_{j=1}^{m 2} \delta_{2 j} \Delta z_{t-j}+\sum_{j=1}^{m 3} \delta_{3 j} \Delta x_{f t-j}+e_{1 t} \\
& \Delta y_{t}=\delta_{0}+\sum_{j=1}^{m 1} \delta_{1 j} \Delta y_{t-j}+\sum_{j=1}^{m 2} \delta_{2 j} \Delta z_{t-j}+\sum_{j=1}^{m 3} \delta_{3 j} \Delta x_{m t-j}+e_{1 t}
\end{aligned}
$$

where $x_{f t}$ is female education and $x_{m t}$ is male education.
Eq. (2) represents the impact of female education at a particular level on growth and Eq. (3) represents the same for males.

\section{Analyses}

\section{Introduction of model}

The model is specifying the impact of primary, secondary and tertiary education on economic growth. The dependent variable is GDP per capital. Individual equations aim to explain the GDP per capital development in relation to education and human capital stock at all levels and also with respect to gender and fertility rate issues. Endogenous variable is: $\mathrm{Y}=\mathrm{GDP}$ per capita (in constant 2005 USD), Exogenous variables are:

\section{Statistical description of variables}

Initially, independent variables have been tested for the presence of multicollinearity. A correlation matrix has been created. Surprisingly, no values of correlation between the variables exceeded 0.7 and hence the authors kept all variables in the model in unchanged form.

In India between the years 1971 to 2003 there was an enormous gap between male and female enrolment rates at primary and secondary level. However, starting in 2004, the gap began to diminish.

Human capital stock is measured in relations to the educational attainment level, with the average years of education level from the age of 15 and above. According to Self and Grabowski (2004), the human capital stock measure is typically lower than the enrolment rate and it shows the difference between male and female population.

I: Lag Selection for general education

VAR Lag Order Selection Criteria

Endogenous variables: Y X2 X3 X4 X5

Sample: 19712011

Included observations: 38

\begin{tabular}{lcccccc}
\hline Lag & LogL & LR & FPE & AIC & SIC & HQ \\
\hline $\mathbf{0}$ & -998.8089 & NA & $6.06 \mathrm{e}+16$ & 52.83205 & 53.04752 & 52.90871 \\
$\mathbf{1}$ & -720.5214 & 468.6947 & $9.97 \mathrm{e}+10$ & 39.50112 & 40.79396 & 39.96110 \\
$\mathbf{2}$ & -672.6652 & $68.00609 *$ & $3.22 \mathrm{e}+10$ & 38.29817 & $40.66836^{*}$ & $39.14147^{*}$ \\
$\mathbf{3}$ & -640.8295 & 36.86242 & $2.72 \mathrm{e}+10^{*}$ & $37.93840^{*}$ & 41.38594 & 39.16501 \\
\hline
\end{tabular}

* indicates lag order selected by the criterion

LR: sequential modified LR test statistic (each test at $5 \%$ level)

FPE: Final prediction error

AIC: Akaike information criterion

SIC: Schwarz information criterion

Source: own compilation 
II: Cointegration between general education and economic growth

Dependent Variable: DLNY

Method: Fully Modified Least Squares (FMOLS)

Sample (adjusted): 19742011

Included observations: 38 after adjustments

Cointegrating equation deterministic: $\mathbf{C}$

Long-run covariance estimate (Bartlett kernel, Newey-West fixed bandwidth $=4.0000$ )

\begin{tabular}{lcccc}
\hline \multicolumn{1}{c}{ Variable } & Coefficient & Std. Error & t-Statistic & Prob. \\
\hline DDLNX2 & 3.099346 & 0.754997 & 4.105111 & 0.0002 \\
DLNX3 & 0.100647 & 0.235271 & 0.427793 & 0.6716 \\
DLNX4 & 0.000440 & 0.185331 & 0.002372 & 0.9981 \\
DLNX5 & 0.179459 & 0.057488 & 3.121695 & 0.0037 \\
C & 0.022926 & 0.006727 & 3.408231 & 0.0017 \\
\hline R-squared & 0.285236 & Mean dependent var & 0.036369 & \\
Adjusted R-squared & 0.198598 & S.D. dependent var & 0.030607 & \\
S.E. of regression & 0.027400 & Sum squared resid & 0.024774 & \\
Long-run variance & 0.000612 & & & \\
\hline Source: & & &
\end{tabular}

Source: own compilation

III: Lag selection for female education.

VAR Lag Order Selection Criteria

Endogenous variables: Y X2 X6 X7 X8 X12 X13 X14 X15 X20

Sample: 19702011

Included observations: 39

\begin{tabular}{|c|c|c|c|c|c|c|}
\hline Lag & $\log L$ & LR & FPE & AIC & SC & HQ \\
\hline 0 & -607.5860 & NA & 26.90788 & 31.67108 & 32.09763 & 31.82412 \\
\hline 1 & 29.18151 & 914.3328 & $3.50 \mathrm{e}-11$ & 4.144538 & $8.836635^{*}$ & 5.828022 \\
\hline 2 & 202.0298 & $159.5523 *$ & $2.54 \mathrm{e}-12 *$ & $0.408727^{*}$ & 9.366367 & $3.622651 *$ \\
\hline
\end{tabular}

Source: own compilation

IV: Cointegration between female education and growth

Dependent Variable: DLNY

Method: Fully Modified Least Squares (FMOLS)

Sample (adjusted): 19742011

Included observations: 38 after adjustments

Cointegrating equation deterministic: $\mathbf{C}$

Long-run covariance estimate (Bartlett kernel, Newey-West fixed bandwidth $=4.0000$ )

\begin{tabular}{lcccc}
\hline \multicolumn{1}{c}{ Variable } & Coefficient & Std. Error & t-Statistic & Prob. \\
\hline DDLNX2 & 2.349652 & 0.691388 & 3.398457 & 0.0020 \\
DLNX6 & 0.139516 & 0.154347 & 0.903912 & 0.3735 \\
DLNX7 & -0.017962 & 0.119190 & -0.150698 & 0.8813 \\
DLNX8 & 0.165442 & 0.048375 & 3.419977 & 0.0019 \\
DLNX12 & -0.763246 & 0.740742 & -1.030380 & 0.3113 \\
DLNX13 & 0.542758 & 0.597412 & 0.908515 & 0.3711 \\
DLNX14 & 0.195044 & 0.189223 & 1.030765 & 0.3112 \\
DLNX15 & -0.132538 & 0.041846 & -3.167262 & 0.0036 \\
C & 0.033195 & 0.008382 & 3.960165 & 0.0004 \\
\hline R-squared & 0.501272 & Mean dependent var & 0.036369 & \\
Adjusted R-squared & 0.363692 & S.D. dependent var & 0.030607 & \\
S.E. of regression & 0.024415 & Sum squared resid & 0.017286 & \\
\hline
\end{tabular}

Source: own compilation 
V: Lag selection for male education

VAR Lag Order Selection Criteria

Endogenous variables: DLNY DDLNX2 DLNX9 DLNX10 DLNX11 DLNX16 DLNX17 DLNX18 DLNX19

Sample: 19712011

Included observations: 37

\begin{tabular}{lccccc}
\hline Lag & LogL & LR & FPE & AIC & SC \\
\hline $\mathbf{0}$ & 858.9125 & NA & $9.03 \mathrm{e}-32$ & -45.94121 & $-45.54937^{*}$ \\
$\mathbf{1}$ & 943.4100 & $123.3208^{*}$ & $8.46 \mathrm{e}-32$ & -46.13027 & -42.21182 \\
$\mathbf{2}$ & 1043.421 & 97.30804 & $7.07 \mathrm{e}-32 *$ & $-47.15790^{*}$ & -39.71284 \\
\hline
\end{tabular}

Source: own compilation

VI: Cointegration between male education and growth

Dependent Variable: DLNY

Method: Fully Modified Least Squares (FMOLS)

Sample (adjusted): 19742011

Included observations: 38 after adjustments

Cointegrating equation deterministic: $\mathbf{C}$

Long-run covariance estimate (Bartlett kernel, Newey-West fixed bandwidth $=4.0000$ )

\begin{tabular}{lcccc}
\hline \multicolumn{1}{c}{ Variable } & Coefficient & Std. Error & t-Statistic & Prob. \\
\hline DDLNX2 & 1.818162 & 0.616985 & 2.946851 & 0.0063 \\
DLNX9 & 0.302644 & 0.200225 & 1.511520 & 0.1415 \\
DLNX10 & -0.277678 & 0.141953 & -1.956118 & 0.0601 \\
DLNX11 & 0.118324 & 0.055570 & 2.129295 & 0.0418 \\
DLNX16 & 0.459521 & 0.795445 & 0.577690 & 0.5679 \\
DLNX17 & -0.596238 & 0.610077 & -0.977315 & 0.3365 \\
DLNX18 & -0.395737 & 0.237500 & -1.666260 & 0.1064 \\
DLNX19 & -0.003949 & 0.084302 & -0.046844 & 0.9630 \\
C & 0.051882 & 0.009945 & 5.216620 & 0.0000 \\
\hline R-squared & 0.517563 & Mean dependent var & 0.036369 & \\
Adjusted R-squared & 0.384477 & S.D. dependent var & 0.030607 & \\
S.E. of regression & 0.024013 & Sum squared resid & 0.016722 & \\
Long-run variance & 0.000366 & & & \\
\hline Source:
\end{tabular}

Source: own compilation

Equation using to analyze the male education and growth:

$d l n y=d \ln y_{t-1}+d l n y_{t-2}+d l n y_{t-3}+$

$+d d \ln x_{2}+d d \ln x_{2 t-1}+d d l n x_{2 t-2}+$

$+d l n x_{9}+d l n x_{9 t-1}+d l n x_{9 t-2}+d l n x_{9 t-3}+$

$+d \ln x_{10}+d \ln x_{10 t-1}+d \ln x_{10 t-2}+d \ln x_{10 t-3}+$

$+d \ln x_{11}+d \ln x_{11 t-1}+d \ln x_{11 t-2}+d l n x_{11 t-3}+$

$+d \ln x_{16}+d \ln x_{16 t-1}+d l n x_{16 t-2}+d l n x_{16 t-3}+$

$+d \ln x_{17}+d \ln x_{17 t-1}+d \ln x_{17 t-2}+d \ln x_{17 t-3}+$

$+d l n x_{18}+d l n x_{18 t-1}+d l n x_{18 t-2}+d l n x_{18 t-3}+$

$+d \ln x_{19}+d \ln x_{19 t-1}+d \ln x_{19 t-2}+d \ln x_{19 t-3}+$

\section{RESULTS}

\section{Primary education and growth}

As it is depicted in the Tab. VII, primary education is not closely correlated with economic growth.
However, the gross enrolment rate for primary females with and without fertility rate has a casual impact on capital stock, which means that primary education has an indirect impact on economic growth with a $95 \%$ chance of probability.

\section{Secondary Education and Growth}

In Tab. VIII, there are displayed results which suggest that there is not a large difference between the primary and secondary level of education in terms of their impact on the economic growth. On the other hand, there is a significant impact of gross enrolment rate for secondary level of educations of female population with and without fertility rate on the human capital stock with $96 \%$ probability. Also, for human capital stock, it showed that the secondary female education negatively affects the number of children born with $95 \%$ probability. 
VII: Casual relation at primary level

\begin{tabular}{lcc}
\hline \multicolumn{1}{c}{ Direction of causality: education to growth } & G-Causality (P-value) & Cointegration (P-value) \\
\hline General & No $(0.6719)$ & No $(0.6716)$ \\
Enrolment & & \\
Gender based & No $(0.5468)$ & No $(0.1415)$ \\
Enrolment-male & No $(0.3426)$ & No $(0.3735)$ \\
Enrolment-female-without fertility & No $(0.3426)$ & No $(0.5438)$ \\
Enrolment-female-with fertility & No $(0.8517)$ & No $(0.3365)$ \\
Change in human capital stock-male & No $(0.2194)$ & No $(0.3711)$ \\
Change in human capital stock-female without fertility & No $(0.2194)$ & No $(0.5566)$ \\
\hline Change in human capital stock-female with fertility & &
\end{tabular}

Source: own compilation

VIII: Casual relation at secondary level

\begin{tabular}{lcc}
\hline \multicolumn{1}{c}{ Direction of causality: education to growth } & G-Causality (P-value) & Cointegration (P-value) \\
\hline General & No $(0.1318)$ & No $(0.9981)$ \\
Enrolment & & \\
Gender based & No $(0.4307)$ & No $(0.0601)$ \\
Enrolment-male & No $(0.3309)$ & No $(0.8813)$ \\
Enrolment-female-without fertility & No $(0.3309)$ & No $(0.9832)$ \\
Enrolment-female-with fertility & No $(0.1036)$ & No $(0.1064)$ \\
Change in human capital stock-male & No $(0.0816)$ & No $(0.3112)$ \\
Change in human capital stock-female without fertility & No $(0.0816)$ & No $(0.5925)$ \\
\hline Change in human capital stock-female with fertility & &
\end{tabular}

Source: own compilation

IX: Causal relation at tertiary level

\begin{tabular}{lcc}
\hline \multicolumn{1}{c}{ Direction of causality: education to growth } & G-Causality (P-value) & Cointegration (P-value) \\
\hline General & No $(0.6959)$ & Yes** $(0.0037)$ \\
Enrolment & & \\
Gender based & No $(0.0946)$ & Yes* $(0.0418)$ \\
Enrolment-male & No $(0.9430)$ & Yes** $(0.0019)$ \\
Enrolment-female-without fertility & No $(0.9430)$ & Yes** $(0.0006)$ \\
Enrolment-female-with fertility & Yes** $(0.0010)$ & No $(0.9630)$ \\
Change in human capital stock-male & No $(0.3456)$ & Yes** $(0.0036)$ \\
Change in human capital stock-female without fertility & No $(0.3456)$ & Yes** $(0.0001)$ \\
\hline Change in human capital stock-female with fertility & &
\end{tabular}

Source: own compilation

\section{Tertiary Education and Growth}

In Tab. IX, there are depicted results of tertiary education that strongly correlate with economic growth. The female population at the tertiary level of education, for both variables with and without the inclusion of the fertility rate variable, reflects a causal long term impact on the economic growth. However, for the male population results showed positive correlation with the economic growth only for the enrolment rate. On the other hand, the impact of the average years of tertiary education on the economic growth can be seen only in the short term period. 


\section{CONCLUSION}

The determinants of education at primary, secondary and tertiary level were analyzed in depth along with the economic growth in India. Quality education, along with the level of education, and its impact on the economy has been studied by many researchers and evidence from their publications show that education is an important factor in enhancing and promoting economic growth. This is true in many countries, especially in developing countries such as India. In order to test the hypothesis, GDP per capital was defined by the model as dependent variable on the capital stock, gross school enrolment rate and average years of schooling at every level of education for both genders. The autocorrelation and normality of the residuals test has been conducted. The $\mathrm{p}$-value in all econometrics tests proved that the null-hypothesis cannot be rejected. Parameters were verified statistically, economically and econometrically.

Our results correspond with the results of Kingdon (2007) who examined the level of education in India and they correspond also with the results of Self \& Grabowski (2004) proved that primary and secondary education is not just strongly correlated with the economic growth of the country but it also has a strong casual impact on the economic growth in India. Many other publications focused on researching the relationship of the level of education and economic growth of the country. Some publications also focused on the similar topic in broader region such as East Asia. In his work, McMahon (1998) also identified positive relationship between education level and economic growth Our results provided an evidence that with respect to education, economic growth of India is positively related to the starting level of average years of schooling of males and females at the tertiary level of education. The evidence shows that female education at all levels has the potential for generating economic growth. However, for males the result appears to have a causal impact on economic growth only at the tertiary level. When the results were verified and compared with the hypotheses, it was concluded that not all of the results support the two stated hypotheses. The first hypothesis was to verify whether the secondary education has a positive impact on economic growth in India, specifically for female population. However, after the analysis of the data gathered it was discovered that tertiary education causes an economic growth in India and it is true for both genders. On the other hand, from the results it is obvious that there is a significant impact of gross enrolment rate for secondary level of educations of female population (with and without fertility rate) on the human capital stock. This most likely means that if women enroll in the study they tend to finish the studies which lead to higher human capital. This has another effect as for human capital stock, results showed that the secondary female education negatively affects the number of children born with $95 \%$ probability.

The second hypothesis is that the level of education has an indirect impact on economic growth through the fertility rate in India. It was proven that fertility rate has an indirect impact on economic growth through the primary and secondary education of females. This proved the second hypothesis to be valid. This phenomenon could be explained many ways. One reason behind this could be that people with higher education might be more cautious and plan their future carefully which results also in planning of the family thus the fertility rate decreases as females proceed with higher levels of education.

In conclusion, it can be stated that tertiary education is the main causal force in the economic growth in India but this is true mainly for male population. The higher quality of education, the greater impact of education on the economic growth. The impact should be evident but only after certain period of time as the impact might not be ascertainable immediately. Also, there are some shortcomings of this research. Some of them are, e. g. a possibility of not including important variables in the models, focus on only one country instead of inclusion of cross-country analysis. On the other hand, this research focused on India in depth and provided some valuable new evidence. Another example of shortcoming is the measure for each level of education as enrolment rates and average years of schooling as they are extensively used, but they are problematic in many ways. Human capital stock is accumulated (meaning that if person wants to complete secondary level of education that person also needs to pass the previous level of education) and therefore it is difficult to measure it. There exist different approaches to calculation of human capital stock and it might be worth of comparing the results with different approach to calculations. Due to many shortcomings, further research using more extensive data sets along with inclusion of more variables and different method of calculation of human capital is certainly required and recommended. 


\section{REFERENCES}

AGGARWAL, J. C. 2008. Educational Reforms in India (for the 21st century). 3rd Revised Edition. New Delhi: Shipra Publications.

AZARIADIS, C. and DRAZEN, A. 1990. Threshold Externalities in Economic Development. Quarterly Journal of Economics, 105(2): 501-26.

BEHRMAN, J. R. 1987. Schooling in Developing Countries: Which Countries Are the Over- and Underachievers and What Is the Schooling Impact? Economics of Education Review, 6(1): 111-127.

CLARK, J. S., SMUTKA, L., CECHURA, L. et al. 2015. The Law of One Price and the Czech Cereal Market Integration into the EU Common Agricultural Market. Ekonomický časopis/Journal of Economics, 63(8): 817-836.

D'ALEO, V. and SERGI, B. S. 2017. Human factor: the competitive advantage driver of the EU's logistics sector. International journal of production research, 55(3): 642-655

DURAISAMY, P. 2002. Changes in returns to education in India, 1983-94: by gender, age-cohort and location. Economics of Education Review, 21(6): 609-622.

EASTERLIN, R. A. 1981. Why isn't the Whole World Developed? Journal of Economic History, 41(1): 1-19.

GLEWWE, P. and KREMER, M. 2006. Schools, Teachers, and Education Outcomes in Developing Countries. In: HANUSHEK, E. and WELCH, F. (Eds.). Handbook of the Economics of Education. Vol. 2. $1^{\text {st }}$ Edition, 945-1017.

GRANGER, C. W. J. 1969. Investigating Causal Relations by Econometric Models and Cross-spectral Methods. Econometrica, 37(3): 424-438.

KHARCHEVA, I., KONTSEVAYA, S. and MAITAH, M., 2016. Analysis Of Manpower Resources Utilization in Agriculture Organizations Of The Russian Federation. In: Economic Science for Rural Development No. 42. Jelgava, Latvia, 21-22 April 2016. pp. 244-249.

KINGDON, G. G. 2007. The Progress of School Education in India. Oxford Review of Economic Policy, 23(2): 168-195.

LIN, T-C. 2003. Education, Technical Progress, and Economic Growth: The Case of Taiwan. Economics of Education Review, 22(2): 213-220.

LIN, T-C. 2004. The Role of Higher Education in Economic Development: An Empirical Study of Taiwan Case. Journal of Asian Economics, 15(2): 355-371.

MAITAH, M. and SMUTKA, L. 2016. Restoration and Growth of the Russian Sugar Market. Sugar Tech, 18(2): 115-123.

MAITAH, M., SALEEM, N., MALEC, K, BOUBAKER, M. and GOUDA, S. 2015. Economic value added and stock market development in Egypt. Asian Social Science, 11(3): 126-134.

MAITAH, M., MUSTOFA, J. and UGUR, G. 2017. The Impact of Terrorist Attacks on Foreign Exchange Rate: Case Study of Turkish Lira versus Pound Sterling. Economies, 5(1): 5.

MAITAH, M., HAYAT, A., MALEC, K. and ELDEEB, O. 2014. The impact of foreign direct investments on employment in the Czech Republic. Reserach Journal of Applied Sciences, 9(12): 1001-1008.

NATIONAL PORTAL OF INDIA. 2015. India.gov.in: national portal of india. [Online]. Available at: https://india. gov.in [Accessed: 2015, January 1].

ŘEZBOVÁ, H., MAITAH, M. and SERGIENKO, O. I. 2015. EU quota sugar market concentration - the main drivers of EU sugar market. Agris On-line Papers in Economics and Informatics, 7(4): 131-142.

SELF, S. and GRABOWSKI, R. 2004. Does education at all levels cause growth? India, a case study. Economics of Education Review, 23: 47-55.

SINGH, K. and AWASTHI, A. 2016. Impact Of Foreign Direct Investment On Higher Education International Journal of Research-Granthaalayah, 4(5): 80-91.

SMUTKA, L., ZHURAVLEVA, E., PULKRABEK, J. et al. 2015. Russian Federation- Sugar Beet and Sugar Production. Listy Cukrovarnicke a Reparske, 131(2): 72-77.

STEVENS, P. and WEALE, M. 2003. Education and Economic Growth. National Institute of Economic and Social Research Discussion Paper. [Online]. Available at: http://cee.lse.ac.uk/conference_papers/28_11_2003/ martin_weale.pdf [Accessed 2015, January 1].

TILAK, J. B. G. 2007. Post-elementary education, poverty and development in India. International Journal of Educational Development, 27(4): 435-445.

UNESCO. 2002. Education for All - Is the World on Track? United Nations Educational, Scientific and Cultural Organization.

UNESCO. 2006. EFA - Literacy for life, United Nations Educational, Scientific and Cultural Organization.

UNESCO. 2010. Reaching the Marginalized, United Nations Educational, Scientific and Cultural Organization.

WAMBOYE, E., ADEKOLA, A. and SERGI, B. S. 2015. Internationalisation of the campus and curriculum: evidence from the US institutions of higher learning. Journal of higher education policy and management, 37(4): 385-399.

WORLD BANK. 2015. India. The World Bank Data. [Online]. Available at: http://data.worldbank.org/ country/india [Accessed: 2015, January 1]. 
Contact information

Mansoor Maitah:maitah@pef.czu.cz

Petr Procházka:pprochazka@pef.czu.cz

Luboš Smutka: smutka@pef.czu.cz

Markéta Kopecká:kepcka.mar@email.cz

Vladimír Hönig: vladimir.honig@vse.cz

Sylvie Kobzev Kotásková: kotaskova@pef.czu.cz 